\title{
Finite Element Analysis Simulation of Side Automobile Safety Airbag Unfolding Process
}

\author{
Hanwu Liu ${ }^{a}$, Haimei Feng ${ }^{b}$, Xiaobin Wang ${ }^{c}$, Yonghui Gao ${ }^{d}$ \\ Sch. of Mechanical and Electrical Engineering, North China Institute of Science and Technology, \\ Sanhe, Hebei, 065201, China \\ ahanwu-liu@sohu.com, b543505993@qq.com, '985726181@qq.com, d863276480@qq.com
}

Keywords: Airbag, Nylon 66, Collision, Temperature, Forecast

\begin{abstract}
With the development of transportation industry, there're more and more traffic accidents caused by the vehicle driving, bring great potential safety hazard and economic risks to the drivers and their families. Therefore, it's of great importance to take a study on airbag application especially on computer simulation of airbag unfolding. In this paper, the airbag made of Nylon 66 unfolding process and stress and strain distribution between human and the car during the frontal collision was finite analyzed. The results showed that, when the crash occurs human body moves forward because of inertia and touches or impacts the unfolded airbag. During that process most energy is absorbed, giving buffer to the violent collision between human body and airbag with a equivalent stress of 0.0043MP. The result provides a theoretical basis and reference to predicting the possibility of various situations during crash and improving airbag stability.
\end{abstract}

\section{Introduction}

In traffic collision accidents, frontal impact accounts for 55\% -60\%.And in traffic accidents that lead to severe injury and death, frontal impact accounts for 70\%and 50\% separately. Frontal impact refers to impact occurred on the front of the car and within 30 degrees range of the vehicle axis. As an auxiliary configuration of the vehicle body for safety, the airbag can largely reduce or avoid injury when a traffic accident happens. Therefore, it is attracting more and more attention. When the crash occurrs, in order to make passengers and driver "Flutter in the airbag" because of inertia, airbag will open an air cushion between passengers and vehicle components before "Secondary impact", protecting drivers from injury by absorbing impact energy.

Because that study of airbag test costs a lot and is time-consuming in the real vehicle crash $t$ and simulation impact test. Consequently, the use of computer simulation of airbag work and of the interaction of airbags and dummy has been extensively developed. By using computer simulation method, safety performance of the vehicle structure can be predicted in the design stage. Besides, the force and deformation analysis of each mechanical part can be detailed in the process of collision. According to the simulation results and the change the structure design constantly, ultimately, we can get the optimal structure design Meeting the collision safety performance.

Multi-body dynamics methods and dynamic nonlinear finite element method of large deformation is often used in computer simulation. In multi-body dynamics methods, using a rigid body and various dynamic hinges are used to describe the system, this method can be used to analysis large strain system. Multi-body dynamics is simple in modeling and is time saving, is widely-used in security technology field that analyzing dynamic response of the interaction between human and vehicle components. This method is usually used in the design and development stage of new Vehicle. Dynamic nonlinear finite element method of large deformation can be applied for analyzing the nonlinear of structures and materials relative accurately by simulation in problems, such as structural deformation, displacement, velocity, acceleration and other parameters. This method is usually used in the ultimate validation stage of important vehicle components and new vehicle. In this paper, the process of air bag unfolding is numerically simulated, aim to find a way to mitigate the injuries in greatest degree when vehicle crash happens. 


\section{Numerical simulation of airbag unfolding process}

Parameters of certain vehicle hidden airbag are showed in Tab.1, and the airbag is 3D modeled according to the table. Human body is simplified as adult head model with radius of $75 \mathrm{~mm}$. The analysis process is made up with molding, meshing, loading and constraint condition

Table 1 parameters of airbag

\begin{tabular}{cccccc}
\hline Volume & $\begin{array}{c}\text { Young } \\
\text { modulus }\end{array}$ & Poisson ratio & dessity & permeable factor & thickness \\
& $\mathrm{L}$ & $\mathrm{MPa}$ & $\mathrm{g} / \mathrm{mm} 3$ & $\mathrm{~mm}$ & \\
50 & 200 & 0.2034 & 721.667 & 0 & 0.003 \\
\hline
\end{tabular}

In pre-processing, Windows notepad is used to revise K file, and pass it to LS-DYNA Solver for solution. After that, LS-PREPOST 2.4Beta is applied for post processing.

The process of airbag unfolding and crashing with human head at $25^{\circ} \mathrm{C}$ is shown in Fig. 1 , which can be departed into three stages.

1. The car crashes with obstacle in front at a speed of $30 \mathrm{~km} / \mathrm{h}$, human head moved forward at the acceleration of $8.6 \mathrm{~m} / \mathrm{s} 2$. At the same time, the safety airbag system is in the stage in which senor feel the strength of the car crash and pass it to the controller that accept and process the signal. This stage costs $15.984 \mathrm{~ms}$

2. The car stopped after crash, and speed turns to 0, but human head move forward at a speed of 8.6 $\mathrm{m} / \mathrm{s} 2$ because of inertia. When the senor accepts the signal that the crash strength has reached the predetermined threshold, it sends ignition signal immediately to trigger gas generator. Then the gas generator release lots of gas immediately after ignition and the gas bag is unfolded completely, as is shown in Fig.1, when $\mathrm{t}=23.986 \mathrm{~ms}$. This stage lasts for $13.016 \mathrm{~ms}$. Then, human head moves towards to the airbag, airbag is unfolded gradually and gets its largest volume at the time $t=28 \mathrm{~ms}$, when human head is to crash with airbag.

3. Human head moves forward and crashes with the completely unfolded gas bag. Most of the human head kinetic energy is absorbed by airbag, giving buffer to the secondary crash between human body and airbag and protecting human body, as is shown in Fig. 1 when $t=31.999 \mathrm{~ms}$, $\mathrm{t}=33.999 \mathrm{~ms}$. As shown in Fig. $1 \mathrm{t}=36.001 \mathrm{~ms}$, speed of human head decreases to 0, most energy is absorbed, this stage lasts for $8.001 \mathrm{~ms}$.

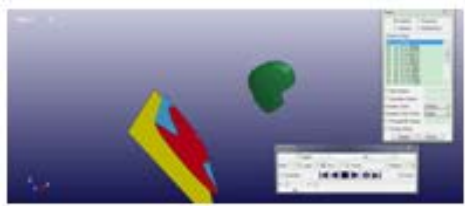

$\mathrm{t}=0 \mathrm{~ms}$

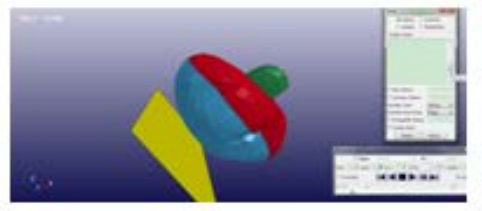

$\mathrm{t}=31.999 \mathrm{~ms}$

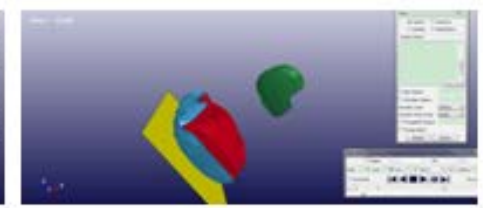

$\mathrm{t}=23.986 \mathrm{~ms}$

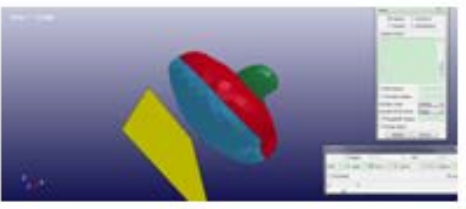

$\mathrm{t}=33.999 \mathrm{~ms}$

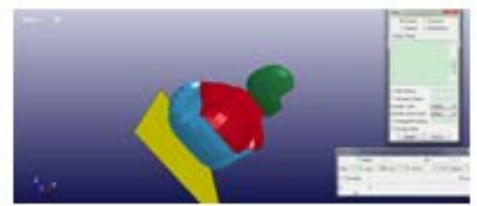

$\mathrm{t}=28 \mathrm{~ms}$

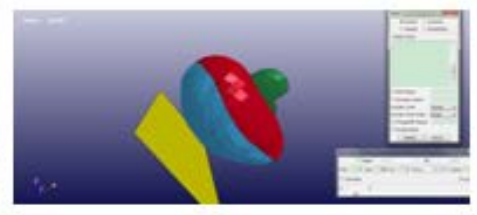

$\mathrm{t}=36.001 \mathrm{~ms}$

Fig. 1 simulation results of the gasbag unfold process

\section{Analysis of Stress Distribution in Collision}

During the airbag unfold process, the strain distribution changes with time. It's described as follows in detail.

As shown in Fig.2, when the collision happens, little stress appears in airbag, when $\mathrm{t}=0 \mathrm{~ms}$ 、 $\mathrm{t}=23.986 \mathrm{~ms}$, certain deformation appears because of frontal impact, then corresponding stress is generated.

When the senor in airbag accepts the signal that the crash strength has reached the predetermined threshold, the airbag is unfolded completely. Then human body begins to touch with airbag, at this 
time stress in airbag gets larger and changes quickly, as shown in Fig.2 when $t=28 \mathrm{~ms}, \mathrm{t}=31.999 \mathrm{~ms}$, $\mathrm{t}=33.999 \mathrm{~ms}$. In this stage, stress gets large and rise quickly, but it's not big enough to cause airbag blasting.

The gas volume is largest when human body gets completely impact with airbag, as shown in Fig.2 $\mathrm{t}=36.001 \mathrm{~ms}$, at which moment the deformation get largest causing largest stress correspondingly. But, it can be seen that human body equivalent stress is only $0.0043 \mathrm{Mpa}$, indicating that harm and effect caused by frontal impact will be small, due to the well protection provided by airbag.

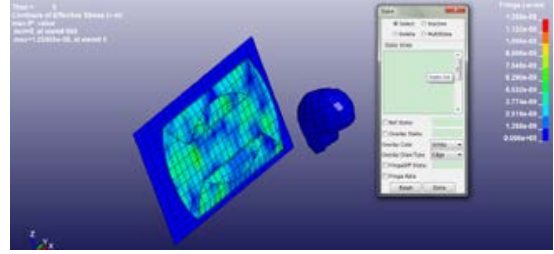

$\mathrm{t}=0 \mathrm{~ms}$

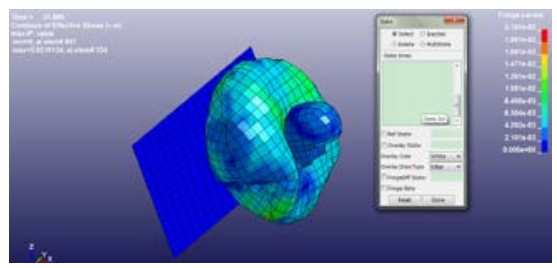

$\mathrm{t}=31.999 \mathrm{~ms}$

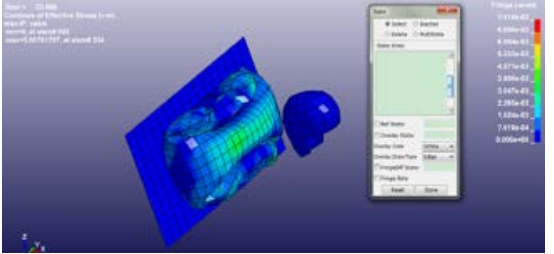

$\mathrm{t}=23.986 \mathrm{~ms}$

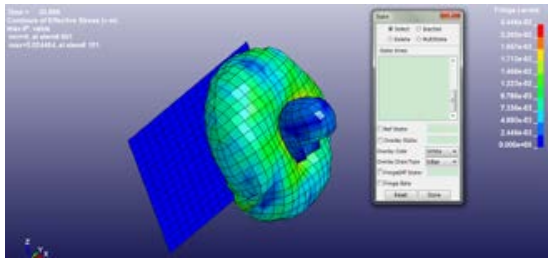

$\mathrm{t}=33.999 \mathrm{~ms}$

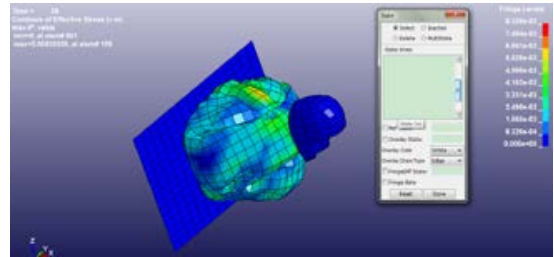

$\mathrm{t}=28 \mathrm{~ms}$

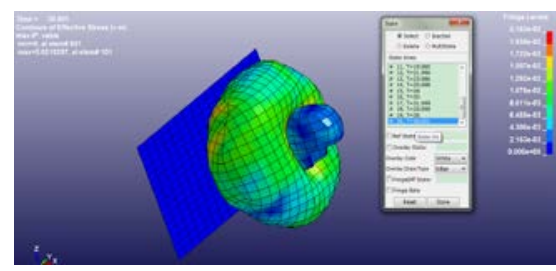

$\mathrm{t}=36.001 \mathrm{~ms}$

Fig. 2 Stress Analysis during gasbag unfolding process

\section{Analysis of Strain Distribution in Collision}

During the airbag unfold process, the strain distribution changes with time. It's described as follows in detail.

As shown in Fig.3 when $\mathrm{t}=36.001 \mathrm{~ms}$, little strain appears in airbag and is concentrated in airbag in similar with stress analysis. At this moment, the airbag is still in the folding sate, human body keeps moving forward and no stress appears.

When the senor in airbag accepts the signal that the crash strength has reached the predetermined threshold, the airbag is unfolded completely. Then human body begins to touch with airbag, as shown in Fig. 3 when $t=28 \mathrm{~ms}, t=31.999 \mathrm{~ms}, \mathrm{t}=33.999 \mathrm{~ms}$. At these moments, strain in airbag is large, airbag get unfolded with order from senor, and large amounts of gas dash into airbag with strain and stress increasing gradually.

When human body gets completely impact with airbag as shown in Fig. $3 t=36.001 \mathrm{~ms}$, the gas volume is largest as a result of which the strain get largest. However, it can be seen from Fig. 3 that the human head equivalent strain turns to 0 , so as to the region touching with human head. Area with larger strain appears around the perimeter of the completely unfolded airbag. Therefore, it's obviously that airbag can well protect human head 


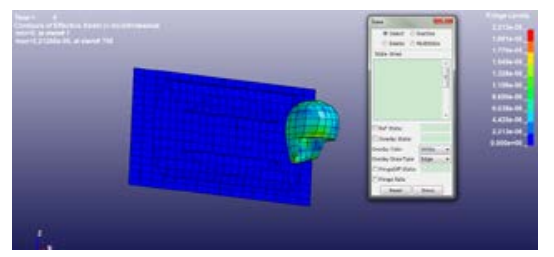

$\mathrm{t}=0 \mathrm{~ms}$

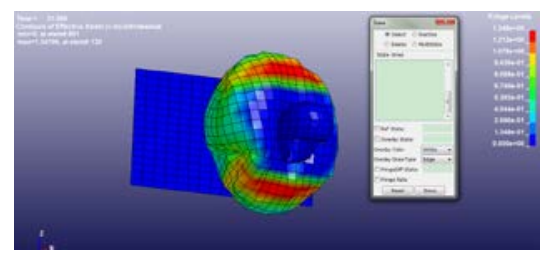

$\mathrm{t}=31.999 \mathrm{~ms}$

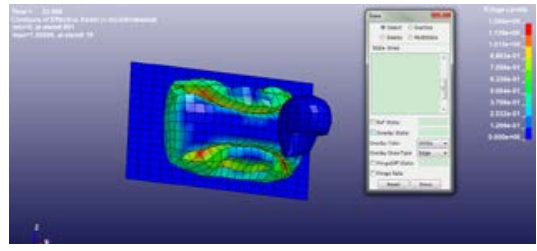

$\mathrm{t}=23.986 \mathrm{~ms}$

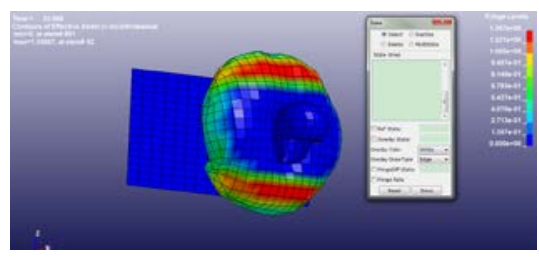

$\mathrm{t}=33.999$

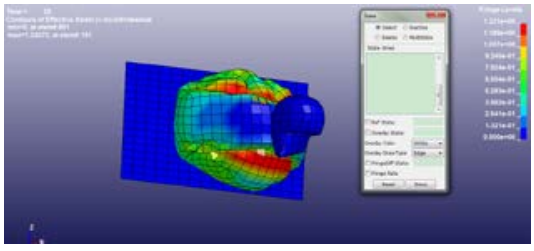

$\mathrm{t}=28 \mathrm{~ms}$

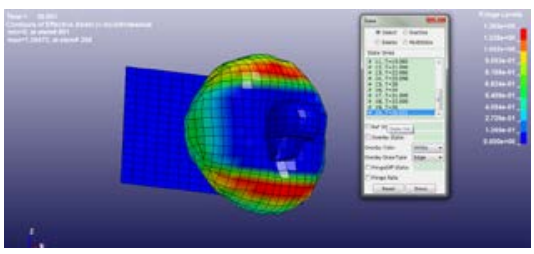

$\mathrm{t}=36.001 \mathrm{~ms}$

Fig. 3 Strain Analysis during gasbag unfolding process

\section{Conclusion}

According to actual work condition of fascia board hidden side airbag, this paper adopts mapping mesh method and direct airbag folding method based on finite element technique, realizing dynamic simulation of the process from air inflation to unfold completely and the collision process of airbag and human body, some conclusions are drawn:

1. In this paper finite element technique is adopted to analyze the unfolding process in frontal impact, obtaining the airbag stress and strain distribution which provides a theoretical basis and reference to predicting the possibility of various situations during crash and improving airbag stability.

2. During airbag unfolding process, human head moves forward and crashes with the completely unfolded gas bag. Most of the human head kinetic energy is absorbed by airbag, making body movement speed reduce gradually to 0 , rather than crash with other part of the car, protecting human body from being hurt effectively.

3. According to analysis of airbag unfolding process and strain-stress distribution, it's known that the maximum airbag equivalent stress is only $0.015 \mathrm{Mpa}$ and the maximum human body equivalent stress is only $0.0043 \mathrm{Mpa}$. As to equivalent strain, the airbag is about 1.365 , while there is little strain appearing in human body, improving that airbag can well protect safety of the driver in frontal impact.

\section{References}

[1] Jinhuan Zhang. Safety Design of Vehicle Crash,Beijing: Tsinghua university press, 2010.(In China)

[2] Yuhang Wang, Weigao Qiao. Study on Vehicle model methods based on CAE, Shanghai Auto,2008(12).(In China)

[3] Lina Mao, Huifeng Zhang. Shape analysis and optimization of airbag for space inflatable antenna, Journal of Harbin Institute of Technology, 2011(03)

[4] ZHUANG Junyuan, LI Dongjun, BI Ying, et.al. Optimization of Vehicle Side Curtain Airbag Module Based on Computer Aided Engineering, Chinese Journal of Mechanical Engineering, 2009(04)

[5] Shihui You, Zhihua Zhong. Current and Trend of Computer Simulation of Vehicle Airbag , Journal of Hunan University,2000(03).(In China) 
[6] Xinming Wan, Tao Yang, Jikuang Yang. Application of Airbag Fold Parametric Design Based on Method, Computer Simulation, 2006(05).(In China) 